\title{
Supporting Engineering Students' Self-Efficacy in a Flipped Calculus II Course
}

\section{Dr. John Kerrigan, Rutgers University}

John earned his Ed.D. in Design of Learning Environments at Rutgers University and actively works with both the Mathematics Department and Graduate School of Education at Rutgers University to design active learning environments conducive to high-level learning. John is currently on the P2C2 Committee in the Math Department which aims to transform the landscape of Pre-Calculus through Calculus 2 instruction to include more active learning opportunities. John has taught a variety of courses, ranging from the new Pre-Calculus for Engineers course to capstone courses for future teachers.

\section{Dr. Lydia Prendergast, Rutgers University, School of Engineering}

Assistant Dean for Academic Services Interests: Active learning in STEM, Course transformations, Faculty development.

\section{Jillian A.S. Mellen, Rutgers University, New Brunswick}

Jillian is a senior undergraduate student studying Astrophysics at Rutgers University in New Brunswick, where she is also a teaching assistant. Her primary research area is in physics education and she hopes to attend graduate school to continue researching. She is a mother of two and the president of a local non-profit organization representing a diverse urban elementary school.

\section{Dr. Geraldine L Cochran \\ Antonio D Silva}




\section{Supporting Engineering Students' Self-Efficacy in a Flipped Calculus II Course}

\author{
John Kerrigan \\ Rutgers University
}

\author{
Lydia Prendergast \\ Rutgers University
}

\author{
Geraldine Cochran \\ Rutgers University
}

\author{
Jillian Mellen \\ Rutgers University
}

\author{
Antonio Silva \\ Rutgers University
}

\section{Introduction}

Engineering education research has shown that there are several factors that impact students' attitudes and efficacy beliefs in engineering, which can tip the scales in the students' decision or ability to stay in engineering [1]. Gateway courses to advanced study in engineering, such as Calculus II, have been historically perceived by students to be the most difficult [2]. Anecdotal reasons for this could include the complexity of the calculus curriculum, the amount of background knowledge needed to keep pace with learning, and lack of time for concept exploration and engagement during class. Studies have shown that self-efficacy is more predictive of mathematics performance than prior mathematics experiences and measures of mathematics anxiety [3], [4].

Self-efficacy can be defined as an individual's belief in their innate ability to achieve goals, and is based on both skill mastery and self-confidence [5], [6]. Self-efficacy has been shown to be an important mediating factor involved in students' achievement in coursework [7]. In addition to self-efficacy, the classroom pedagogical setting plays a large role in students' experiences and performance. Historically, college-level calculus courses are often set within a traditional lecture setting with teacher-centered instruction and minimal student engagement.

Implementing a "flipped classroom" approach to learning has been shown to improve learning outcomes in STEM courses by increasing students' self-efficacy and engagement and maximizing learning [8], [9], [10]. Flipped classrooms generally involve empowering students to initially learn content outside of class through streaming media, followed by extensive in-class application of content with support from peers and instructional staff. Previous work on the flipped classroom approach in undergraduate mathematics education, specifically in the calculus sequence, has largely focused on performance differences on posttests between students in a flipped classroom and their counterparts in traditional lectures [11], [12]. Some studies have also focused on students' and instructors' perceptions of the flipped classroom approach [13]. Recognizing the need to look beyond performance differences, several researchers have started to look at the important dimensions of self-regulation and self-efficacy in the flipped classroom. 
For example, Sun, Xie, and Anderman [10] found that students achieved a higher level of confidence in learning undergraduate mathematics in a flipped classroom setting compared to their peers in a traditional learning setting. These effects were enhanced by collaboration with other peers in the classroom.

Recognizing the importance that both self-efficacy and active learning methods play in learning and persistence in STEM, we sought to explore students' self-efficacy in a flipped undergraduate gateway Calculus II classroom. Our study addressed two research questions: (1) How does the self-efficacy of math/physical science students in a flipped Calculus II course change over the course of one semester? and (2) What is the perception of math/physical science students regarding the use of flipped teaching strategy in a Calculus II course? This paper outlines the course design features, quantitative self-efficacy data collected from students over the course of a term, and qualitative interview data from students in the course. Findings from this study can help further research in understanding the classroom-related factors that can improve retention in engineering programs.

\section{Setting for Research}

The research study took place in a Calculus II course for students pursuing a STEM major. The course is called "Calculus II for Math and Physical Science Majors" and is referred to as "Math 152." This section describes the structure of the course before and after the pedagogical changes.

\section{Traditional Structure and Content}

During the academic year, Math 152 is taught during both fall and spring semesters, in a largelecture format. Approximately 90 students meet in a lecture hall twice a week for an 80-minute lecture. Each week, students also attend one 80-minute recitation (30 students) that is led by a graduate Teaching Assistant (TA). The TA works in conjunction with the lecturer to provide smaller group instruction: reviewing homework problems, reviewing concepts learned during lecture, and assessing students on their mastery of the week's lecture. During the summer, the course is condensed into eight weeks, and the students are taught only by the instructor, three times a week for approximately 150 minutes each meeting. The time students would have spent in recitation becomes additional time in class for either lecturing, small group activities, and/or assessment.

Regardless of the term, the course covers the same wide scope of content at the same level of difficulty. The course begins with the fundamental concepts of integration by substitution, area, and volume. Then the course rapidly progresses into a full unit on integration strategies. The second unit is devoted to a full treatment of sequences and series. In this unit, students explore many applications, including those related to Taylor Series and Geometric Series. The course concludes with the calculus of polar, parametric, and complex coordinate systems. 


\section{Summer Student Population}

For this particular summer session, 33\% of students in Math 152 were engineers. The remaining students had majors in a variety of mathematics, computer science, and physical science areas. This is consistent with the typical makeup of a Math 152 section during the academic year. During the 2018-2019 academic year, 32\% of students who enrolled in Math 152 were engineering majors.

The summer term presents its own unique challenges to both the instructor and the students. Many students who take Math 152 in the summer have taken it at least once before and were not successful. A second group of students come from Math 135, which is Calculus I designed for students who are not pursuing a STEM as a major. These students come into Math 152 missing some necessary background in trigonometry, differentiation, and integration, and as a result have to work harder to keep up the pace with the rest of the class. The remaining students in Math 152 are either transfer students or students who are trying to advance to Calculus III in the fall by taking Calculus II in the summer session. Meeting three times a week for 150 minutes each class and planning appropriate engaging activities is also difficult for the instructor. Given the wide range of students' backgrounds and twin demands of depth and scope of coverage of the curriculum, teaching Math 152 as a flipped classroom seemed to be a viable pedagogical strategy in which to offer all students increased opportunities for self-directed learning and instructor feedback.

\section{Flipped Classroom Structure}

The flipped classroom instructional design employed in this course allowed for students to (1) engage with multiple representations of mathematics, (2) ask their peers and instructor multiple questions during class time, (3) engage in mathematical inquiry and self-directed learning opportunities, and (4) create a space that promotes self-efficacy and confidence in mathematics. For each class session students were asked to work through a series of instructional videos on the topics at hand. Most in-person meeting sessions covered two textbook sections. Students typically had approximately eight to ten videos to watch before coming to class. In most cases, students had two or three days to complete this work during the condensed summer session. Each video was 8 minutes long or less, adhering to research-based guidelines for flipped classroom video length [14]. The videos used were chosen primarily for their approach: they outlined theory, demonstrated it with visual applets, and then gave concrete examples for students to have as references. Figure 1 shows an example of a video set on numerical integration. 


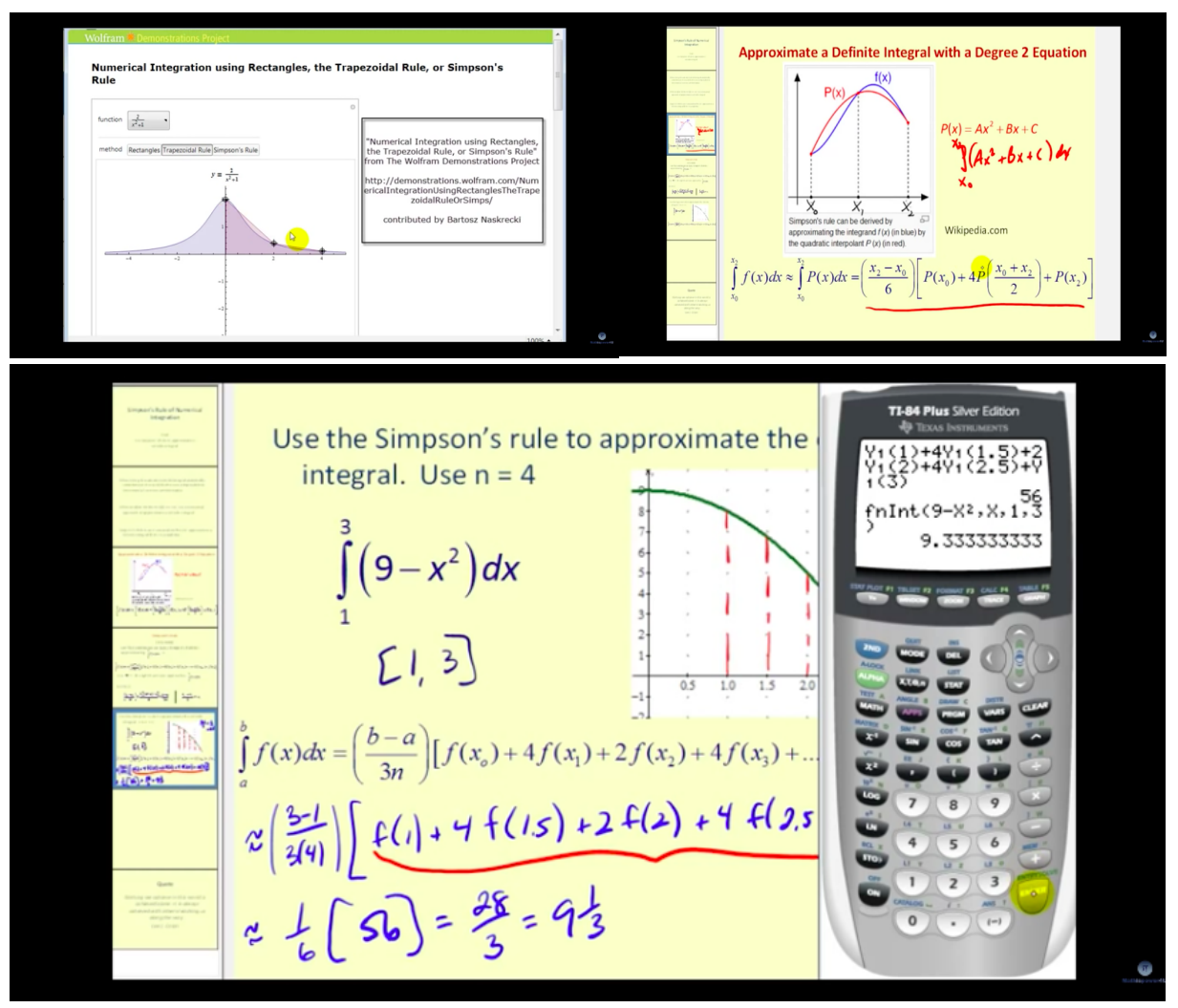

Figure 1. Portions of one instructional video on Simpson's Rule. YouTube Channel Mathispower4u

Students were encouraged to take notes during the videos. Once students watched all of the videos for that section, they were encouraged to read the textbook sections corresponding to the videos for additional examples. Upon arrival to each in-person class meeting, the first ten minutes were devoted to a student-generated summary of the main points of the videos. During this time, students also had the opportunity to ask clarifying questions if they did not already do so via e-mail or in office hours. Following the first ten minutes, students took a brief ten minute quiz consisting of two very basic questions that assessed a surface-level understanding of the videos. The purpose of this quiz was to hold students accountable for watching each video set. Following the quiz, students either went through a two-station rotation or three-station rotation, depending on the activities planned for the class meeting. Two of the stations in both setups included opportunities to work on the WebAssign online homework and to get enrichment and challenge problems. Approximately half of the class sessions had two stations, whereas the other half had three stations.

\section{Workshop Station}

On evenings when there were three rotations, the third was a "workshop" station. All students in the Math 152 track complete workshops each week in an effort to develop effective problemsolving strategies and written mathematical explanation skills. These problems often require 
students to do additional research, connect graphs, tables, and equations, and provide supporting details beyond merely solving a problem. In addition, the workshop problems force students to be metacognitive in order to make personal connections to learning [15]. Students submitted approximately one or two workshops each week to their instructor for a grade which drew on both mathematical accuracy and written explanation. An example of a workshop on the topic of average value is shown in Figure 2.

Problem statement Suppose that the outdoor temperature (in ${ }^{\circ} \mathrm{F}$ ) on a particular day was approximated by the function

$$
T(t)=50+14 \sin \left(\frac{\pi t}{12}\right)
$$

where $t$ is time (in hours) after 9 AM.

a) Find the maximum temperature $T_{\max }$, minimum temperature $T_{\min }$, and average temperature

$$
T_{\text {aver }}=\frac{1}{12} \int_{0}^{12} T(t) d t
$$

on that day during the period between $9 \mathrm{AM}$ and $9 \mathrm{PM}$.

b) Show that $T_{\text {aver }} \neq \frac{1}{2}\left(T_{\min }+T_{\max }\right)$. (This is the definition that the weather bureau uses for "average temperature".)

c) Show that if $T$ is not given by the above formula, but rather $T(t)$ is a linear function of $t$, then $T_{\text {aver }}=\frac{1}{2}\left(T_{\min }+T_{\max }\right)$. (Use either geometric reasoning or an integral.)

Figure 2. Station \#3 workshop prompt example

As shown above, this problem involved students using integrals to find maximum and minimum temperature for a certain day. Then, they had to test the claim that the average temperature could not be calculated by simply averaging a maximum and minimum temperature, but rather by calculating the value of an integral. Students were able to explore this in greater detail by graphing the function, computing area under the curve, and also by looking up weather maps online at their tables.

Figure 3 outlines the sequence of activities in both two-station and three-station rotations. 


\begin{tabular}{|l|l|l|l|l|l|l|}
\hline $\begin{array}{l}\text { Two-station } \\
\text { class }\end{array}$ & $\begin{array}{l}10 \mathrm{~min} \\
\text { review/Q\&A }\end{array}$ & $\begin{array}{l}10 \mathrm{~min} \\
\text { online } \\
\text { quiz }\end{array}$ & $\begin{array}{l}60 \mathrm{~min} \\
\text { Station \#1 }\end{array}$ & $\begin{array}{l}60 \mathrm{~min} \\
\text { Station \#2 }\end{array}$ & $\begin{array}{l}10 \mathrm{~min} \\
\text { online quiz }\end{array}$ & \\
\hline $\begin{array}{l}\text { Three-station } \\
\text { class }\end{array}$ & $\begin{array}{l}10 \mathrm{~min} \\
\text { review/Q\&A }\end{array}$ & $\begin{array}{l}10 \mathrm{~min} \\
\text { online } \\
\text { quiz }\end{array}$ & $\begin{array}{l}40 \mathrm{~min} \\
\text { Station \#1 }\end{array}$ & $\begin{array}{l}40 \mathrm{~min} \\
\text { Station \#2 }\end{array}$ & $\begin{array}{l}40 \mathrm{~min} \\
\text { Station \#3 } \\
\text { (workshop) }\end{array}$ & $\begin{array}{l}10 \text { min } \\
\text { online } \\
\text { quiz }\end{array}$ \\
\hline
\end{tabular}

Figure 3. Class timeline (150 minutes)

\section{Learning Assistant Classroom Support}

An important part of the rotating station design was the availability of an undergraduate Learning Assistant (LA) provided by the University. Undergraduate students who qualify to become an LA have earned an A or B + in the course they are an LA for, successfully completed a course in pedagogy, and have the recommendation of their former instructor. LAs use their pedagogic training to help the instructor facilitate discourse in the classroom to promote active engagement. The LA for this course met with the instructor once a week for each week of the eight-week course to plan, review main ideas of content, and strategize ways to help particular students during class time. Two studies on LA-supported learning environments have shown that students saw dramatic increases in their achievement after working with LAs [16], [17]. Additionally, Van Dusen and Nissen [18] used a critical race theory lens to determine that LA-supported environments decreased failure rates among students in gateway physics courses, particularly among students who are traditionally underrepresented in physics courses. Research has also shown that having an LA improves learning outcomes for faculty as they collaborate with the LA [19].

In this course, during a two-station rotation, students spent approximately one hour working with the LA, while another group sent one hour working with the instructor. After each station, the groups switched. The LA's primary role was to encourage students to peer teach and help one another work through their online assignments housed on the WebAssign platform [20]. WebAssign offers students instant feedback on their answer submissions, along with a suite of scaffolds to support their learning, which include hints and video tutorials. Each WebAssign set consisted of 10-15 questions and allowed students five attempts to answer each question correctly. The instructor provided more challenging problems for students who were looking to explore engineering-related applications and also supplied small group instruction and further scaffolding for students who needed more intensive support. All class sessions ended with 
whole-group closure and an exit quiz, usually consisting of one or two problems that resembled the station work for the class session. Our goal when designing the course was to go beyond the mere inversion of homework and lecture associated with most flipped classrooms and instead offer students more opportunities to work with one another and the instructional team.

\section{Repeat the Cycle}

This cycle repeated itself up until each exam review. Since students had no videos to watch leading up to the exam review class, they instead worked on additional problems and generated questions to ask during class. The actual exam review in-person class consisted of review games, peer teaching opportunities on the wall whiteboards, and additional opportunities for small group instruction by the LA and instructor. After each exam, students resumed the cycle by watching videos to prepare for the next class meeting.

\section{Methods and Participants}

The results of a start-of course demographic survey revealed interesting information about the students, both personally and academically. The twenty-three students in the course came with a wide variety of prior experiences; only $16 \%$ of students previously took a flipped class, $64 \%$ of students reported taking a class with an LA before, and 56\% reported having taken Math 152 in a previous semester. When asked how interested students were in taking this course at the start of the term, $48 \%$ agreed or strongly agreed they were really interested in taking the course, whereas $16 \%$ disagreed or strongly disagreed they were really interested in taking the course. The remaining $36 \%$ were neutral.

The students were racially diverse; $56 \%$ of students were Asian, $32 \%$ White, $8 \%$ Black or African American, and 4\% identified as "Other." Most students (80\%) reported that English was their first language. $67 \%$ of students in this course identified as male whereas $33 \%$ of students identified as female. When asked what they were majoring in, $52 \%$ of students responded with "engineering," $12 \%$ with "computer science," $4 \%$ with "physical science," and the remaining students were either statistics, economics, environmental science, or business majors.

In terms of academic achievement, GPAs varied greatly; $12 \%$ of students reported having a GPA ranging from 3.51-4.0, 44\% had from 3.01-3.5, $8 \%$ had from $2.51-3.00,24 \%$ had from $2.01-2.5$, and the remaining $12 \%$ had from 1.51-2.0. Most students (72\%) reported earning more than 31 credits prior to taking this course, while a small minority (24\%) reported only earning between 13 and 30 credits. One student reported only earning $0-12$ previous college credits. 


\section{Survey}

How does the self-efficacy of math/physical science students in a flipped Calculus II course change over the course of one semester? To answer this research question, students were given the 34-item "Mathematics Self-Efficacy Scale" (MSES) during the first class meeting as a presurvey and last class meeting as a post-survey [21]. The MSES was intended to measure students' beliefs regarding their ability to perform various math-related tasks and behaviors [21]. The MSES had two subscales, the "Mathematics Task Self-Efficacy" subscale and the "MathRelated School Subjects" subscale. Items on the task subscale asked students to rate their confidence on performing mathematics tasks such as, "How much confidence do you have that you could successfully: Add two large numbers (e.g., 5379 + 62543) in your head" [21]. Items on the subjects subscale asked students to rate their confidence on earning grades in certain courses, such as, "How much confidence you have that you could complete the course with a final grade of "A" or "B" in: Basic College Math" [21]. Each survey item had 10 possible response options, that is 0 to 9, corresponding to "No Confidence at All" to "Complete Confidence" on the scale (see Appendix A). Betz and Hackett [21] reported strong evidence for the reliability of items within the MSES, including a Cronbach's alpha value of .96 for the total scale, and .92 for both the Tasks and Courses subscales of the MSES.

\section{Interviews}

What is the perception of math/physical science students regarding the use of flipped teaching strategy in a Calculus II course? To answer this research question, twelve semi-structured interviews [22] were conducted during the last week of class with a focus on gaining a deeper understanding of students' experiences in the flipped classroom. The research team adapted questions from a previous study on students' self-efficacy in calculus [23]. Students names were neither provided nor were known to the interviewer. Each interview was 10-20 minutes long and allowed students to reflect on their self-efficacy in mathematics (see Appendix B). Examples of interview questions included, "How do you rate your confidence in math now? Why?" and "What could make you feel more comfortable about math?" [23]. All interviews were audio recorded using a digital recorder, transcribed, and coded using open coding in order to look for themes. After several passes of open coding, a frequency count was determined for all open codes. Codes were collapsed into larger categories, such as "confidence," "in-class activities," "feelings toward or about mathematics," and "pre-college experiences." After categories were developed, interviewee statements were then categorized as either positive or negative and precollege or college. Interview statements were also marked for self-efficacy opportunities [24] and the kinds of activities described.

\section{Results}

Results are organized by data type as they pertain to each of the two research questions. 


\section{Survey Results}

The pre-surveys and post-surveys were analyzed using a paired t-test, with the pre-survey and post-survey each treated as separate populations. Quantitative data from the pre- and postsurveys indicated changes in students' self-reported self-efficacy from the start of the term to the end of the term. The results showed a significant increase $(\alpha=.05)$ in students' math-related school subjects self-efficacy from a mean of 5.69 with a standard deviation of 1.44 to a mean of 6.25 with a standard deviation of 1.30 and was significant at the 0.05 confidence level. This means that by the end of the course, there was a statistically significant increase in students' reported level of confidence of completing a college-level course with an A or B, from that at the start of the term. The results are summarized in Table 1.

Table 1

Students' Reported Math Related School Subjects Self-Efficacy

\begin{tabular}{|l|c|c|c|c|c|}
\hline $\begin{array}{l}\text { Math-Related School } \\
\text { Subjects Self-Efficacy }\end{array}$ & Mean & SD & $\boldsymbol{n}$ & $\boldsymbol{t}$ & $\boldsymbol{p}$ \\
\hline Pre-Survey & 5.69 & 1.44 & 23 & 2.5225 & .0194 \\
\hline Post-Survey & 6.25 & 1.30 & & & \\
\hline
\end{tabular}

The results also showed a statistically significant increase $(\alpha=.10)$ on the mathematics task self-efficacy subscale, which increased from a mean of 6.62 with a standard deviation of 1.36 to a mean of 6.99 with standard deviation of 1.56. An $\alpha=.10$ was used due to the small sample size. This means that by the end of the course, there was a statistically significant increase in students' reported level of confidence of completing a given task, from that at the start of the term. The results are summarized in Table 2.

Table 2

Students’ Reported Math Task Self-Efficacy

\begin{tabular}{|l|c|c|c|c|c|}
\hline Math Task Self-Efficacy & Mean & SD & $\boldsymbol{n}$ & $\boldsymbol{t}$ & $\boldsymbol{p}$ \\
\hline Pre-Survey & 6.62 & 1.36 & 23 & 1.7648 & .0915 \\
\hline Post-Survey & 6.99 & 1.56 & & & \\
\hline
\end{tabular}

Additionally, the results showed a statistically significant increase $(\alpha=.05)$ in students' total mathematics self-efficacy from a mean of 5.94 with a standard deviation of 1.16 to a mean of 6.42 with a standard deviation of 1.55 and was also significant at the 0.05 confidence level. This 
means there was a significant increase in students' overall self-reported mathematics selfefficacy from the start of the term to the end of the term. The results are summarized in Table 3.

Table 3

Students' Reported Total Math Self-Efficacy

\begin{tabular}{|l|c|c|c|c|c|}
\hline $\begin{array}{l}\text { Total Math } \\
\text { Self-Efficacy }\end{array}$ & Mean & SD & $\boldsymbol{n}$ & $\boldsymbol{t}$ & $\boldsymbol{p}$ \\
\hline Pre-Survey & 6.18 & 1.29 & 23 & 2.3813 & .0263 \\
\hline Post-Survey & 6.64 & 1.36 & & & \\
\hline
\end{tabular}

Upon closer examination of the Math-Related School Subjects portion of the survey, one of the most interesting results that surfaced was students' reported change in calculus self-efficacy from the start of the term to the end of the term. This was particularly important to the research team as the course students were taking was a calculus course. All but one student reported a higher level of calculus self-efficacy from the start of the term to the end of the term, while one student reported no change. Pre-survey results indicated a class mean of 5.30 and standard deviation of 2.38, while post-survey results indicated a class mean of 7.04 and a standard deviation of 1.33. A matched pairs two-tailed t-test produced a $p$-value of 0.0001 and $t$-value of 4.729 . The results are summarized in Table 4.

Table 4

Student's Reported Calculus Self-Efficacy

\begin{tabular}{|l|c|c|c|c|c|}
\hline $\begin{array}{l}\text { Calculus } \\
\text { Self-Efficacy }\end{array}$ & Mean & SD & $\boldsymbol{n}$ & $\boldsymbol{t}$ & $\boldsymbol{p}$ \\
\hline Pre-Survey & 5.30 & 2.38 & 23 & 4.729 & $<.001$ \\
\hline Post-Survey & 7.04 & 1.33 & & & \\
\hline
\end{tabular}

\section{Interview Results}

Based on the results of the coding, there were three major findings that demonstrated an increase in confidence and perception that the classroom design was a good way to learn: (a) experiences in previous math courses, particularly high school, impacted students' perceptions of their selfefficacy in math; (b) active learning increased students' confidence in their ability to do math; and (c) verbal persuasion (implicit encouragement from teachers) positively affected the learning environment. In addition, through their reflections, several engineering students discussed how self-efficacy related to their identities as engineers. 
Experiences in previous mathematics courses. When asked to reflect on their prior experiences in mathematics, we found that students often described how their previous mathematics courses (namely those taken in high school) impacted their self-efficacy in mathematics. Below are a few excerpts from the interviews:

One student favorably discussed a high school teacher who encouraged students to work out problems on the board, and how that subsequently, positively affected the student's self-efficacy: "In high school, I had a teacher that would really just make you like, would put a question on the board and you just have to answer it even if you have no idea how to do it, just like try. And a lot of times like I would just look at the problem like I don't know how to do that, but if I would like even like try if I didn't know, I ended up realizing I knew more than I thought."

Another student positively described their positive interactive learning experiences in high school Pre-Calculus: "My best math teacher would probably be in high school, for precalc because she would make everything interactive, we would work in groups, like work together, be able to ask questions when we needed to."

Interestingly, a student who took the high-school equivalent of Calculus II also discussed how taking this course affected their confidence in Calculus II: "I took calculus BC in high school but it was more of an after school setting and there my teacher I guess in under an hour he went through I guess polar coordinates, and when I saw it on the board I was just blown, I just didn't know what was going on. And when I went back home I opened my books, I went through YouTube videos, I just didn't understand anything. Um, but then when I guess if you're talking about like me coming into this class and becoming more confident, I came to this class, I listened to all the lecture videos and then I came to lecture, and talked to my professor, and he answered all the questions that I had, and it was just having more practice with it is what helped me, because before I just, in lecture, nah, everyone was asking questions..."

These testimonials support the research in that purposefully constructed engaging experiences, also known as "active learning," in and out of the classroom, affect self-efficacy, confidence, and overall learning.

Experiences in the active learning - flipped classroom design. All students provided positive feedback about the flipped classroom design and how it subsequently increased their selfefficacy. Most students referred to the ability to ask questions during class time to be helpful to their learning.

For example, one student said, "I think the class structure, in general made me learn a lot actually, 'cause I've never done this flipped class before, and I actually really like how we get to 
watch videos at home, and we do problems together in class 'cause like before, this is my first time taking math in college, like in high school like we just, we do it the other way around (...) I just think doing problems together is more helpful than lecturing in class."

Another student echoed similar sentiments, and further discussed how active learning leads to greater knowledge gains: "Because we do the problems in class. Lectures he sends a video to watch, so we do that as well. And then so when we come back to class we know like what, what's happening. On the other, I took calc 2 last semester it's every day is a new thing so you just go there and you just learn, half the time you don't know what's going on so you're gonna miss that. And after you're gonna go on like YouTube to search it but you actually missed the main lecture, because you don't know what's happening. Here, you watch videos so he's gonna teach more and do the problems so that way you just refresh it so that way you know more."

Another student described active learning in terms of being able to get help from the instructional team: "I understand the material so much better, able to ask the questions, like I feel comfortable asking the questions because we're interacting with the professor, and the LA the entire time, like it's not just for like two minutes if you approach them at the end of class or everything, so it's definitely a lot better for me."

A fourth student felt active learning in the flipped classroom was a viable way to teach all levels of Calculus: "Like I feel a lot more confident with it, and like, this is like, how I wish like all of the calcs were taught, but I think it's mostly because if I don't understand something, like if I go to other people, or the professors, they're not always there like office hours, I can't always make them, everything like that. So I didn't really have that time or that availability to go during those times, during their office hours, so it's kind of harder now and like watching YouTube videos can only do so much..."

These testimonials support the research in that empowering students to engage in active learning experiences inside the classroom with instructor support positively affects self-efficacy, confidence, and the ability to ask for feedback.

Experiences with verbal persuasion. Last, students reflected on the implicit encouragement offered by the instructional team and how that helped them navigate the Calculus II flipped classroom.

One student said, "Having a teacher right in front of you and if you have a question, I think the only thing that's, that's the barrier in that situation is the student being scared to ask a question. But being in an environment where you're encouraged to ask questions that's much more helpful. 
But here, we're actually coming to class and we're not just listening to him, we're actually asking questions. And so that's the difference, not just listening to someone talking about a topic but you know having more interaction."

Another student talked about getting help in a smaller group format, and how that promoted understanding: "I think that increased my confidence, because I know that then like I understood my question, the subjects that pertained to the topics in my question, I knew I understood those very well because I had the opportunity for ten minutes to just talk about those with other people, just work about that problem instead of like focusing on all those topics at once like having a whole sheet of questions in front of me that like was probably gonna stress me out if I see like twenty questions as opposed to one that I could just like fully understand."

These shared perspectives from students, coupled with the previous findings of the importance of active learning and previous mathematics courses, suggest that positive verbal persuasion also helped support positive students' self-efficacy in Calculus II.

Experiences with engineering reflections. Several students discussed their experiences learning Calculus II by describing the impact it has had on their future careers in STEM fields.

When two students in a focus group were asked if their self-confidence improved since the start of class, one said, "It definitely increased 'cause at the same time we learned calc 2 [the instructor] also taught us how the calc 2 can connect with applications. Outside applications and he actually showed it in class. And that's the reason you know you will be using all that stuff in your career that you will be choosing."

The other student said, "Same thing I think it has increased for me too because usually like I'm used to teachers that just say alright this is your problem, do it, figure it out. So, and also it is better for me 'cause of civil engineering I will be working hands on especially with that like buildings, houses, bridges anything that will just help me out. So more confidence the better I'll do."

In a similar fashion, in another group, a student described the impact flipped learning had on his ability to complete tasks outside of class: "As an engineer like some math is actually interesting, like actually building something, you're actually putting stuff together, like for example like um I built a treehouse, yeah, I'm currently building a treehouse like it's almost done, but like getting the wood, measurements and all that stuff so like we can like figure out what to do, that like was something I was interested in, like I didn't mind doing it, it wasn't boring."

Another student felt that the active learning opportunities available in the flipped classroom allowed her to build up confidence to be successful in future mathematics courses:

"Because I know I'm good at math and like most people they can't even get to like this level of math but like here like I'm still able to hold my own. Like I think I hold my own, like I think I'm 
able to do the problems and everything that but I'll be continuing further as an engineer into further maths. So if I can't do this I can't move forward. But I can do this so I know I can move forward."

One student felt more supported in a flipped classroom and described the struggles she has had as a female in engineering: "I feel like this is just coming from my background as a woman in STEM but I do feel like really heavy, unhealthy competition whenever I'm taking a math course and stuff like that, or any engineering course, being in a room full of engineers I hate looking around and I hate that like, I don't know, like the air in that sort of field. And like I know that there's always going to be competition in every field, even if I went for an art major, but um yeah no I just, I do feel a lot of anxiety that I can't be as good as everyone else and I don't think I'm like a good engineer even though I'm not really an engineer, I'm a major in engineering. Like I can always change it, it's just like I feel like math hold me to a high standard that I don't hold myself to because I don't think I can do it."

These comments specific to engineering helped us to further understand the relationship between the course design and students' self-efficacy in mathematics, specifically, how they felt they could perform in their current course and in future courses.

\section{Discussion}

Self-efficacy is an important dimension to consider when designing an undergraduate mathematics classroom learning environment. The kinds of classroom activities in this study seemed to have an impact on students' perceptions of their self-efficacy; multimedia learning, followed by collaborative in-class work with instructor feedback, proved to significantly increase students' perceptions of their self-efficacy, particularly in Calculus II. These experiences can affect students' persistence in engineering and other STEM subjects. In this study, we also found that students' previous experiences with math courses impacted their perception of their selfefficacy. Bandura's work [25] supports this idea, as he found that individuals tend to attribute their self-efficacy to past experiences and how those experiences impacted them. When students reflect on their exposure, or lack of exposure to mathematics courses, it in turn impacts their mathematics self-efficacy [7]. Having positive experiences in mathematics will lead to a more positive self-efficacy. As a result, providing different opportunities for increasing self-efficacy is important for students who enter a course with low self-efficacy, particularly early STEM courses that are part of an engineering curriculum like calculus, physics, and chemistry. Not surprisingly, we also found students were aware of their confidence in math. Discussing and addressing that directly in class may help students with their feelings toward math. Future work

in this area will include a closer look at students' learning outcomes and how they correlate with self-efficacy measures and feedback from interviews. 


\section{References}

[1] L. Prendergast, "Retention, success, and satisfaction of engineering students based on the first-year experience,” Ph.D. Dissertation, Rutgers University, New Brunswick, NJ, 1993. [2] C. S. Kalman and S. Rohar, "Toolbox of activities to support students in a physics gateway course," Physical Review Special Topics-Physics Education Research, vol. 6, no. 2, pp. 1-15, 2010.

[3] F. Pajares and M.D. Miller, "The role of self-efficacy and self-concept beliefs in mathematical problem-solving: A path analysis," Journal of Educational Psychology, vol. 86, pp. 193-203, 1994.

[4] F. Pajares and M.D. Miller, "Mathematics self-efficacy and mathematics outcomes: The need for specificity of assessment," Journal of Counseling Psychology, vol. 42, pp. 190-198, 1995.

[5] M. A. Hutchison, D. K. Follman, M. Sumpter, and G. M. Bodner, "Factors influencing the self-efficacy beliefs of first-year engineering students," Journal of Engineering Education, vol. 95, pp. 39-47, 2006.

[6] M. A. Hutchinson-Green, D. K. Follman, and G. M. Bodner, "Providing a voice: Qualitative investigation of the impact of a first-year engineering experience on students' self-efficacy beliefs," Journal of Engineering Education, vol. 97, pp. 177-190, 2008. [7] J. M. Hall and M. K. Ponton, "Mathematics self-efficacy of college freshman," Journal of Developmental Education, vol. 28, p. 26, 2005.

[8] D. Gross, E.S. Pietri, G. Anderson, K. Moyano-Camihort, and M. J. Graham, "Increased preclass preparation underlies student outcome improvement in the flipped classroom," CBE-Life Sciences Education, vol. 14, ar36., 2015.

[9] W. Maciejewski, "Flipping the calculus classroom: an evaluative study," Teaching Mathematics and its Applications: An International Journal of the IMA, vol. 35, pp. 187-201, 2016.

[10] Z. Sun, K. Xie, and L. H. Anderman, "The role of self-regulated learning in students' success in flipped undergraduate math courses," The Internet and Higher Education, vol. 36, pp. 41-53, 2018.

[11] C. Adams, and A. Dove, "Calculus students flipped out: The impact of flipped learning on Calculus students' achievement and perceptions of learning," PRIMUS, vol. 28, no. 6, pp. 600-615, 2018.

[12] A. S. Albalawi, "The effect of using flipped classroom in teaching calculus on students' achievements at university of Tabuk," International Journal of Research in Education and Science, vol. 4, no. 1, pp. 198-207, 2018.

[13] N. H.Wasserman, C. Quint, S. A.Norris, and T. Carr, "Exploring flipped classroom instruction in Calculus III," International Journal of Science and Mathematics Education, vol. 15 , no. 3, pp. 545-568, 2017.

[14] P. J. Guo, J. Kim, and R. Rubin, "How video production affects student engagement: an empirical study of MOOC videos," In Proceedings of the first ACM conference on Learning @ scale conference,pp. 41-50, 2014.

[15] J. Dunlosky, K.A. Rawson, E.J. Marsh, M.J. Nathan, and D.T. Willingham, "Improving students' learning with effective learning techniques: Promising directions from cognitive and educational psychology." Psychological Science in the Public Interest, vol. 14, no. 1, pp. 4-58, 2013. 
[16] S.J. Pollock, "Longitudinal study of student conceptual understanding in electricity and magnetism," Physical Review Special Topics-Physics Education Research, vol. 5, no. 2, $020110,2009$.

[17] V.K. Otero, "Nationally scaled model for leveraging course transformation with physics teacher preparation," Recruiting and Educating Future Physics Teachers: Case Studies and Effective Practices, pp. 107-116, 2015.

[18] B. Van Dusen and J. Nissen, "Serving marginalized physics students: an HLM investigation of collaborative learning environments," 2018. [Online]. Available: https://arxiv.org/pdf/1805.04788.pdf. [Accessed February 1, 2020]. [19] E.W. Close, J. Conn, and H.G. Close, "Becoming physics people: Development of integrated physics identity through the Learning Assistant experience," Physical Review Physics Education Research, vol. 12, no.1, 010109, 2016.

[20] Cengage WebAssign, 2020. [Online]. Available: https://webassign.com. [Accessed February 1, 2020].

[21] N. E. Betz, and G. Hackett, "Mathematics self-efficacy scale," Palo Alto, CA: Mind Garden Press, 1993.

[22] H.J. Rubin and I.S. Rubin, Qualitative interviewing: The art of hearing data. Thousand Oaks, CA: Sage, 2011.

[23] C.E. Monterrosa, “Latino and African American Students' Self-Efficacy in AP Calculus Courses" Ph.D. Dissertation, California State University, East Bay, CA, 2015.

[24] V. Sawtelle, E. Brewe, R.M. Goertzen, and L.H. Kramer, "Identifying events that impact self-efficacy in physics learning," Physical Review Special Topics-Physics Education Research, vol. 8, no. 2, 020111, 2012.

[25] A. Bandura, "Self-efficacy: toward a unifying theory of behavioral change," Psychological Review, vol. 84, no. 2., p. 191, 1977. 


\section{Appendix A}

\section{Mathematics Self-Efficacy Scale}

All of the MSES items are scored on a ten point Likert scale from 0 to 9:

No Confidence at All Very Little Confidence Some Confidence Much Confidence Complete Confidence 0 123

Part I. How much confidence do you have that you could successfully:

7. Calculate recipe quantities for a dinner for 3 when the original recipe is for 12 people.

12. Compute your income taxes for the year.

18. Figure out how much lumber you need to buy in order to build a set of bookshelves.

Part II. Rate the following college courses according to how much confidence you have that you could complete the course with a final grade of "A" or "B."

27. Geometry

33. Advanced Calculus

Note: The five sample MSES items are reprinted under license from the copyright holder, Mind Garden, Inc. 


\section{Appendix B}

\section{Focus Group Interview Protocol}

The purpose of this interview is to understand how different classroom environments might affect someone's confidence in their ability to do math. Thus, I would like to ask you a few questions about how you feel about different math classes, math teachers, and just math. This is a semi-structured interview meaning that I have a list of 5 main questions that I will ask you and that everyone being interviewed will be/has been asked. However, depending on your responses, I may ask follow up questions or ask you to elaborate on your responses. Sometimes, I may repeat back things that you said in my own words to make sure that I understand what you mean. If I do that and what I say does not reflect what you mean, please, inform me. This interview is voluntary and you can choose to stop participating at any time. Just let me know and I will stop recording. I will also let you know before I start recording. Do you have any questions? Are you ready to start? Okay, I am going to hit record now as soon as I hit record, I will ask you again if I have your permission to record in order to have it on record.

1. Tell me a story that explains something about the type of student you are in math. In other words, share with me something that happened to you that involves this subject and perhaps your parents, teachers, or friends.

a. How did this impact your mastery of math classes?

2. Describe the best teacher you've had in math. What made her (or him) so good?

3. Think about how math makes you feel. You probably haven't been asked to think about that before. When you are given a math test, how does that make you feel? How do you feel when you are given a math assignment?

4. Earlier you rated your math ability on a scale of 0 to 9 . How would you rate your confidence in math now? Why?

5. What could make you feel more confident about yourself in math?

Adapted from: Monterrosa, C. E. (2015). Latino and African American Students' Self-Efficacy in AP Calculus Courses (Doctoral dissertation). 